\title{
Questioningthemutualbenefitsofmyrmecochory:a stableisotope-basedexperimentalapproach
}

\author{
STEPHANE CAUT, ${ }^{1}$ M I CHAEL J. J OWER S, ${ }^{1}$ XIM CER D A ${ }^{1}$ and \\ R A P H A E L R . B O U L A Y ${ }^{2,3}{ }^{1}$ Estación Biológica de Doñana. Consejo Superior de Investigaciones Científicas \\ (CSIC), Departamento de Etología y Conservación de la Biodiversidad, Sevilla, Spain, ${ }^{2}$ Departamento de Zoología, Universidad \\ de Granada, Granada, Spain and ${ }^{3}$ Institut de Recherche sur la Biologie de 1'Insecte UMR CNRS 7261, Université François \\ Rabelais, Tours, France
}

\begin{abstract}
Mutualisms play a key part in ecological systems and drive the evolution of much of the world's biological diversity. Among them, myrmecochory, seed dispersal by ants, is a worldwide mechanism throughout many ecosystems. However, the classic representation of myrmechocory as a mutualism could be put into question if one of the two players did not garner a real advantage.

2. A controlled diet experiment was conducted in which ants were given five diets (supplemented or not with elaiosomes). First, using an ant-seed mutualism system, the aim was to understand if elaiosome consumption could modify reproductive output and sex allocation. Second, nitrogen isotopic values were used as a nutrient tracer in the brood to estimate the consumption and selection of elaiosome in comparison to other diets.

3. A significant difference was found in the production of pupae between some diets, but pupae production was not linked to the elaiosome supplementation. Repartitions between pupa type and the effect of the diets were also not significantly different. Moreover, the nitrogen isotopic values of pupae differed among diets but not pupa types.

4. The mutualistic aspects of myrmechory remain unclear, especially when it comes to estimating the benefits to ants. It is clear that ants assimilate the elaiosome nutrients, but the effect of this assimilation on the reproductive output or sex allocation appears limited. Elaiosomes could provide a nutritional advantage under certain conditions when resources are scarce (qualitative or quantitative), but they are not nutritionally required, and thus represent a food source with no specific advantage to the ant.
\end{abstract}

Keywords. Aphaenogastersenilis, Helleborusfoetidus, nutrient transfer, sex allocation, stable isotope.

\section{Introduction}

Seed dispersal by animals is an ecologically important phenomenon that contributes to the regeneration of many plant communities around the world (Willson \& Traveset, 2000). Most animal-assisted seed dispersal events consist of mutualistic interactions, whereby a food reward is tightly

Correspondence: Stephane Caut, Estación Biológica de Doñana. Consejo Superior de Investigaciones Científicas (CSIC), Departamento de Etología y Conservación de la Biodiversidad, Sevilla, Spain.

E-mail: stephanecaut@gmail.com associated with the seed, so that animals that attempt to pick up the former also transport the latter. In short, plants and animals exchange food for dispersal (Herrera, 2005). In contrast to other mutualisms, tightly coevolved pair-wise seed dispersal interactions are not the rule. Moreover, seed-dispersal mutualisms are generally asymmetric in that plants depend exclusively on animals for dispersal, whereas animals may use a wide variety of alternative resources apart from the seedassociated rewards. Hence, many seed dispersal mutualisms involve guilds of consumers that have broad diets. This lack of specificity may make seed-dispersal mutualisms particularly susceptible to exploitative parasitism (Bronstein, 1994; Van 
Ommeren \& Whitham, 2002; MacRaild et al ., 2010). For instance, animals may feed on both the reward and the seed, or eat the reward without transporting the seed. On the other hand, plants may cheat by manipulating animal behaviour, providing cheap cues that promote seed removal behaviour but that have a poor nutritional value (Pfeiffer etal ., 2010; Vereecken \& McNeil, 2010).

Myrmecochory, seed dispersal by ants, is a worldwide interaction involving more than 11000 plant species $(4.5 \%$ of all species) and many ant species across most terrestrial ecosystems (see review, Lengyel et al ., 2010). Myrmecochorous seeds bear a small appendage, the elaiosome, which is attractive to ants. Often, ants gather the whole diaspores (i.e. seeds with elaiosomes), carry them to the nest, eat the elaiosome, and discard the seeds within or outside the nest (Giladi, 2006). Plant benefits as a result of myrmecochory are well documented and include dispersal from the parent plant, protection from predators, reduced seedling competition, avoidance of fire, or relocation of the seeds to more favourable microsites (i.e. the nest) for survival, germination, and plant establishment (reviewed in Giladi, 2006). Myrmecochory has traditionally been considered a widespread interaction involving hundreds of ant species (Lengyel etal ., 2010). However, it was recently shown that, locally, plants often rely on a handful of 'keystone' mutualists because many ant species detach the elaiosomes at the site without transporting the seeds, thus acting as exploitative parasites (Manzaneda etal ., 2007; Boulay etal ., 2007a; Zelikova etal ., 2008; Ness etal ., 2009; Aranda-Rickert \& Fracchia, 2010).

Elaiosomes mainly contain lipids, some proteins, carbohydrates, and vitamins (Fischer etal ., 2008; Pfeiffer etal ., 2010). Behavioural bioassays conducted on various ant species indicate that 1,2 diolein and, to a lesser extent, oleic acid trigger the removal behaviour by ants (e.g., Pizo \& Oliveira, 2001; Gammans etal ., 2005; Boulay etal ., 2006; Pfeiffer etal ., 2010). These compounds are also present in insect corpses, suggesting that the chemical composition and the behavioural releaser in elaiosomes had converged to be similar to that of ant invertebrate prey (Hughes etal ., 1994). If so, the elaisosome would simply be 'a dead insect analogue' (Carroll \& Janzen, 1973). Attracting carnivorous and omnivorous ants may represent an advantage for the plant because, unlike granivorous ants, they are less likely to damage seed embryos (Hölldobler \& Wilson, 1990; Gammans etal ., 2006).

What happens once the diaspores have been transported to the nest has been investigated in only a few studies, and the observed effects vary greatly (Table 1), leading some authors to compare the ant nest to a 'blackbox' (Servigne \& Detrain, 2010). Elaiosomes are mostly offered to larvae. When they were added to Aphaenogaster rudis' Enzmann diet in the field, their consumption was shown to increase the proportion of diploid larvae developing into queens instead of workers (Morales \& Heithaus, 1998; but see Bono \& Heithaus, 2002). Other previous studies conducted in the laboratory have shown an increase in the production of workers but not sexuals in Myrmicaruginodis Nylander and M. rubra Linnaeus (Gammans et al ., 2005; Fokuhl et al ., 2007). In Temnothorax crassispinus, the elaiosome supply increased female weight and decreased male weight (Fokuhl et al ., 2011). Finally, adding Datura elaiosome-bearing seeds to an artificial standard diet had no effect on queen survival or brood production in Pogonomyrmex californicus Emery (Marussich, 2006).

The previous results raise the question of the possible manipulation of ant behaviour by plants. Gomez etal . (2005) have shown that the elaiosome structure can serve as a handle improving seed manipulation by ants. Pfeiffer etal . (2010) confirmed these results and demonstrated that chemical mimicry and deception also occur in myrmecochorous plants. In the present study, we aimed to elucidate (i) if the elaiosome is really consumed and assimilated by the ants, (ii) if the elaiosome is preferred and selected compared with two other diets, and (iii) if the assimilation of elaiosomes could modify the colony reproductive output and sex allocation. We conducted a controlled diet experiment using a common Mediterranean ant-seed mutualism system (Aphaenogaster senilis Mayr -Helleborusfoetidus ) and analysed both larval development and elaiosome consumption using stable isotopes. Stable isotope analysis has proven to be a useful tool in reconstructing diets, characterising trophic relationships, elucidating patterns of resource allocation, and constructing food webs (see review Caut et al ., 2009; Feldhaar et al ., 2010). Using this approach, we could trace the level of isotopic assimilation of elaiosomes by the brood to estimate their general contribution to both castes' diet and assess if there was differential assimilation between larvae destined to become queens versus workers. Finally, we examined the effect of elaiosome supplementation on reproductive output to elucidate its possible influence on the colony.

\section{Materialsandmethods}

\section{Studyspecies}

Helleborus foetidus L. (Ranunculaceae) is a rhizomatous perennial herb distributed across Western Europe. In the Iberian Peninsula, it grows on mountains from middle to high elevations. The plants produce inflorescences after several seasons of vegetative growth. Flowers have 1-5 carpels (most commonly 2-3), each of which develops 10-12 elaiosome-bearing seeds. Diaspore (seed+elaiosome) fresh mass ranges from 5 to $23 \mathrm{mg}$, and the elaiosome comprises between $\sim 3$ and $15 \%$ of the total diaspore fresh mass. Diaspores are released from the end of June to early July. In the Iberian Peninsula, nearly 40 ant species interact with H.foetidus (Manzaneda etal ., 2007). Ant species belonging to the genus Aphaenogaster, and more specifically A.senilis, behave as legitimate dispersers (i.e. transporting the entire diaspore to the ant nest; Fig. 1). Aphaenogaster senilis is a strictly monogynous ant species distributed around the Western Mediterranean basin. Males and queens are produced throughout the year, with a production peak in early summer, but the species produces most of its brood in spring (Boulay etal ., 2009). At least three larval instars have been identified for the diploid larvae. First and second instars are totipotent and can develop either into workers or queens. However, when 


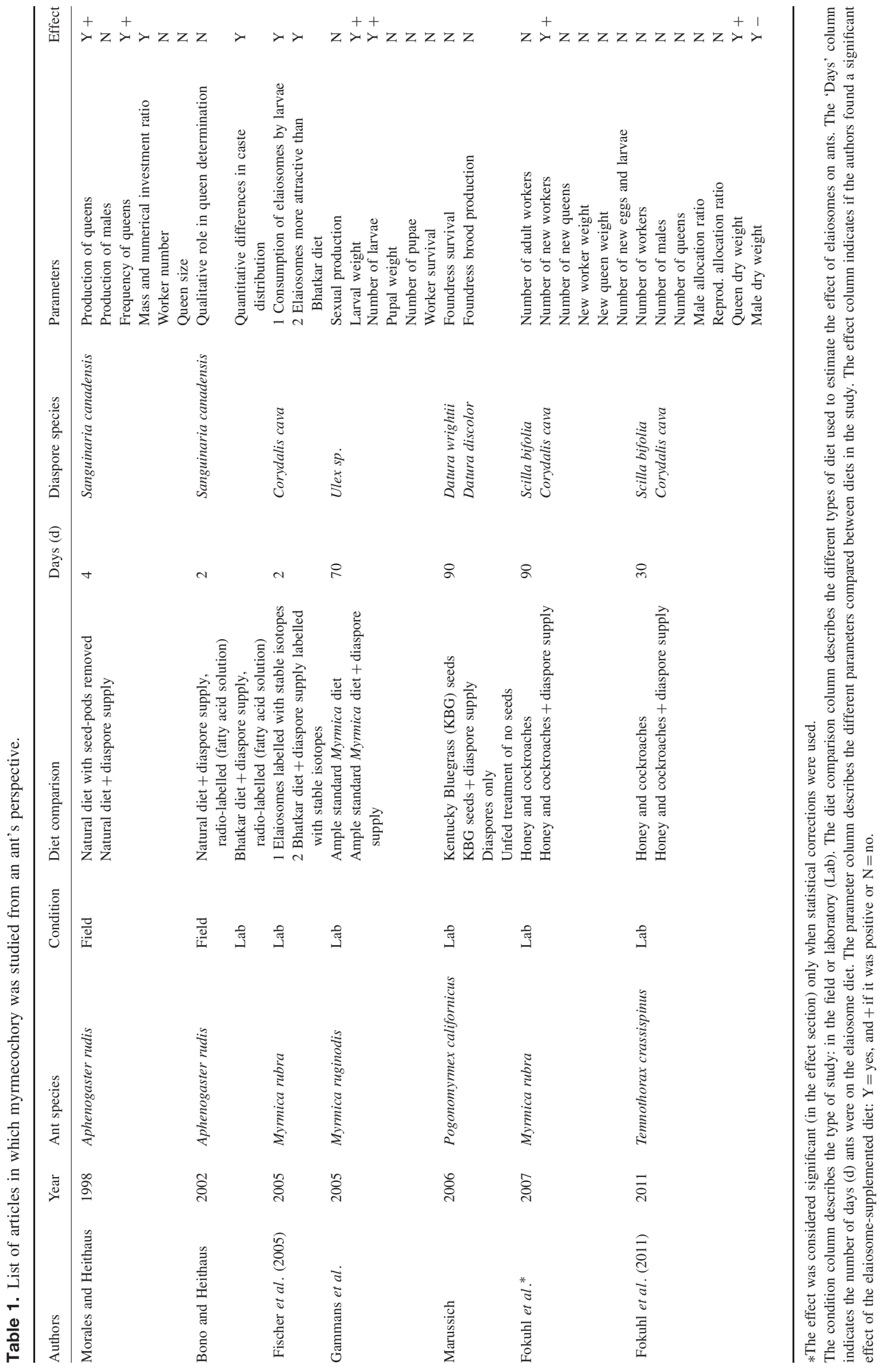


a queen is present in the colony, almost the entire diploid brood develops into workers. Queen death or experimental removal yields the production of one or a few queens from the totipotent larvae. The exact mechanism by which the current queen inhibits the production of other queens is still unknown (Boulay etal ., 2007b, 2009).

\section{Controldietstudy}

All experiments were conducted on 15 medium-sized $A$. senilis colonies collected in Southern Spain in July 2011 and kept in the laboratory. Prior to performing the laboratory experiment, 10 workers and 10 first instar larvae of each colony were collected to analyse their initial isotopic value. Then, each colony was divided into 5 orphan groups of 200 workers, which were kept in artificial nests with a $2 \times 20$-cm (diameter $\times$ length) glass tube half-filled with water for drinking and connected to a $9 \times 7$-cm (diameter $\times$ height) foraging area, the internal wall of which was painted with Fluon to prevent ants from escaping. Each worker group was provided with 20 first instar totipotent larvae. All groups were kept at $28^{\circ} \mathrm{C} \pm 1{ }^{\circ} \mathrm{C}$ in complete darkness. The five orphan groups for each colony were fed every second day and each group received a different diet in a non-limiting quantity: $\mathrm{W}=$ three sliced Tenebrio molitor mealworms; $\mathrm{S}=10$ peeled seeds of Sesamum indicum; $\mathrm{E}=6$ diaspores Helleborus foetidus; $\mathrm{WE}=\operatorname{diet} \mathrm{W}+\mathrm{E}$; or $\mathrm{SE}=\operatorname{diet} \mathrm{S}+\mathrm{E}$. When the ants were offered two composed diets, both foods were presented simultaneously without mashing them up. The consistency of the isotopic composition of the diet was measured on random samples of the individual diets (W, S, and E) five times throughout the experiment.

The presence of queen, worker, and male pupae was checked every second day for 42 days. All the pupae were immediately removed from the groups, dried, weighed, and prepared for isotopic analyses. The remaining adult workers were counted at the end of the experiment. A sample of 10 workers and the remaining larvae were collected to check whether isotopic values had drifted over the course of the experiment.

\section{Isotopicanalyses}

All ant samples (larvae, pupae, and workers) were dried at $60{ }^{\circ} \mathrm{C}$ for $48 \mathrm{~h}$, ground to a fine powder, weighed in tin capsules, and stored in a desiccator until isotope analyses took place. Adult gasters were removed to reduce possible contamination by recently ingested food. Individual measurements of male, worker, and queen pupae from each group were analyzed when available. Adult workers and larvae were pooled per colony (at the beginning of the experiment) and from each colony and grouped at the end of the experiment to obtain sufficient material $(0.5 \mathrm{mg}$ dry weight) for accurate isotope ratio determination.

Isotopic analyses were performed using a continuous flow isotope-ratio mass spectrometry system by means of a Flash HT Plus elemental analyser coupled to a Delta-V
Advantage isotope ratio mass spectrometer via a CONFLO IV interface (Thermo Fisher Scientific, Bremen, Germany) at the Laboratorio de Isótopos Estables of the Estación Biológicade Doñana (LIE-EBD). Ratios are presented as $\delta$ values (\%o), expressed relative to the vPDB (Vienna Peedee Belemnite) standard and to atmospheric $\mathrm{N}_{2}$ for carbon and nitrogen, respectively. Stable $\mathrm{N}$ isotope ratios are expressed as: $\delta^{15} \mathrm{~N}=\left[\left(R_{\text {sample }} / R_{\text {standard }}\right)-1\right] \times 1000$, where $R$ is ${ }^{15} \mathrm{~N} /{ }^{14} \mathrm{~N}$. Reference material was IAEA-N1 $(+0.4 \% \circ)$. One hundred replicate assays of internal laboratory standards indicate measurement maximum errors (SD) of $\pm 0.2 \%$ o for stable nitrogen isotope measurements. The $\mathrm{C} / \mathrm{N}$ ratio was calculated as the total percentage of carbon divided by the total percentage of nitrogen.

\section{Statisticalanalyses}

To compare the effect of diet on larval development, we performed a generalised linear model for each pupae type (worker, queen or male). The dependent variable was the percentage of the selected pupa type (number of pupae/20 $\times 100$ ), and the independent variables were treatment and the number of adult workers that remained at the end of the experiment (as a covariable). The models were fitted with the binomial error distribution and logit link function. We also compared the dry weights of male, worker, and queen pupae across diets. We used linear models in which diet (E, S, W, SE, and WE) was included as a fixed effect (the orphan group was included as a random factor). We used contrast analysis to compare each treatment.

To compare the time to first pupae production among diets and pupa types, we used linear models in which diet $(\mathrm{S}, \mathrm{W}$, $\mathrm{SE}$, and WE) and pupa type were included as fixed effects (the orphan group was included as a random effect).

The differences in $\delta^{15} \mathrm{~N}$ and $\mathrm{C} / \mathrm{N}$ values among the different diets (W, S, and E) were analysed using linear models. When the effect was significant, we used a posthoc Tukey's test to compare diets to each other. To test the isotopic differences between developmental stages at the beginning of the experiment, we compared the $\delta^{15} \mathrm{~N}$ and $\mathrm{C} / \mathrm{N}$ values of workers versus larvae. We used linear models in which the stage was included as a fixed effect.

At the end of the experiment, we compared the $\delta^{15} \mathrm{~N}$ and $\mathrm{C} / \mathrm{N}$ values of the remaining larvae and workers that were fed the different diets. We used linear models in which diet $(\mathrm{E}, \mathrm{S}$, $\mathrm{W}, \mathrm{SE}$, and WE) was included as a fixed effect (the orphan group was included as a random effect). We then added the $\delta^{15} \mathrm{~N}$ and $\mathrm{C} / \mathrm{N}$ values of workers and larvae at the beginning of the experiment to the models, in order to compare their values before and after the dietary treatment began. We used contrast analysis to compare results within each treatment.

Diet assimilation was compared between pupa types by means of a linear model in which diet (S, W, SE, and WE) and pupa type (worker, male, and queen) were included as fixed effects (the orphan group was included as a random effect). We removed the diet $\mathrm{E}$ from the analysis because the production for that diet was very low compared with the other four diets. 


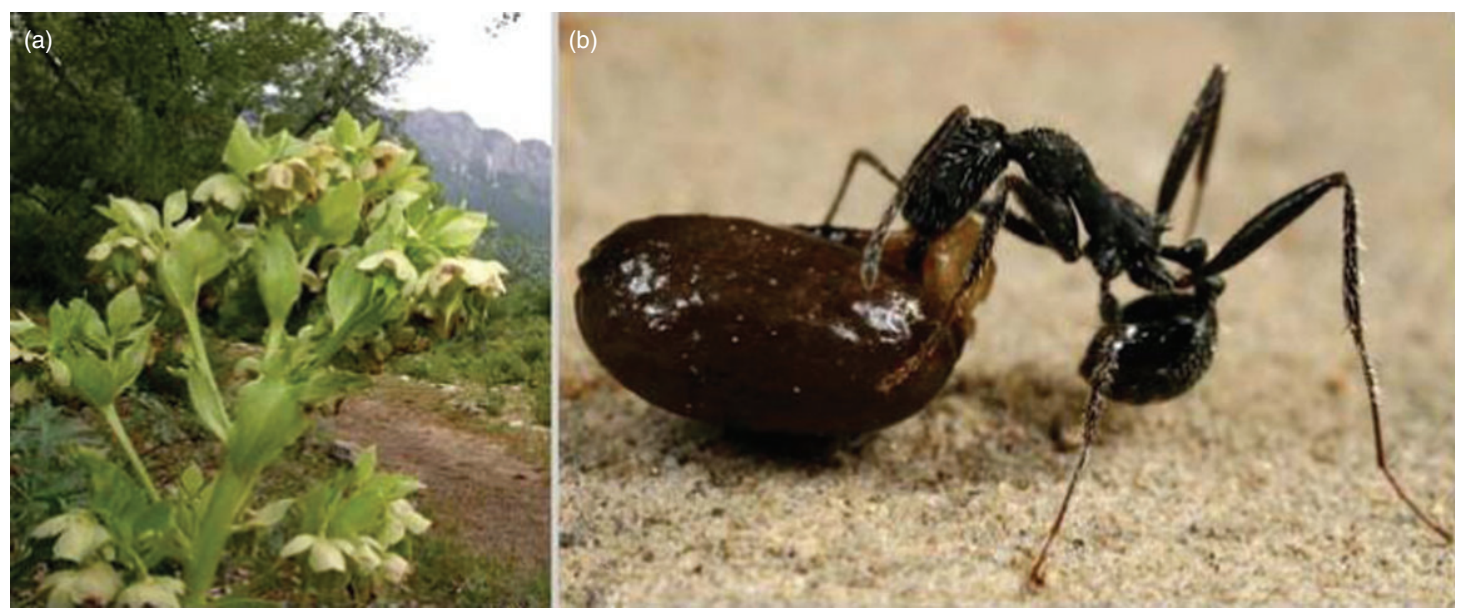

Fig.1. (a) Infructescence of Helleborusfoetidus. Fruit maturation and seed shedding take place in June-July. (b) Aphaenogaster senilis is a disperser of Helleborusfoetidus diasporas. The brown appendage in the diaspore is the lipidic-elaiosome, which is attractive to ants. Photo credits: Fernando Amor.

\section{Results}

\section{Pupaeproduction}

The time to first pupae production was significantly different for different pupa types $\left(F_{2,109}=14.80, P<0.005\right)$, but not for different diet treatments $\left(F_{4,109}=0.54, P=0.705\right)$. The queens were produced significantly earlier than workers and males (queens $=19.8 \pm 0.5$, workers $=25.6 \pm 0.9$, and males $=25.6 \pm 1.5$ days, posthoc $P<0.05$, Fig. 2). On average, $34 \pm 5 \%$ (mean $\pm \mathrm{SE}$ ) of the 20 larvae that were initially provided reached the pupal stage in the $\mathrm{W}, \mathrm{S}$, and respective elaiosome-supplemented groups. Larval development was significantly lower when only elaiosomes were provided (Diet $\left.\mathrm{E}=13 \pm 2 \% ; \chi^{2} 4,69=73.56, P<0.001\right)$. The number of adult workers that remained at the end of the experiment had no effect on larval survival $\left(\chi_{1,69}^{2}=2.63, P=0.105\right)$.

The production of pupae of diploid castes (worker and queen) showed the same general shape for all diets except the elaiosome diet E (Fig. 2). Moreover, while production followed the same pattern in the $\mathrm{S}$ diet, fewer individuals were produced in that treatment compared with the $\mathrm{W}, \mathrm{WE}$, and SE diets, which were very similar to each other (Fig. 2a). The number of adult workers who remained at the end of the experiment had no effect on the percentage of pupae of different types produced (worker; $\chi^{2}{ }_{1,69}=1.62, P=0.204$; queen; $\chi^{2}{ }_{1,69}=0.00, P=0.959$, and male; $\left.\chi^{2}{ }_{1,69}=1.94, P=0.164\right)$.

The percentage of total pupae production was significantly different between diets (W: $38 \pm 5 \%$, WE: $43 \pm 7 \%, \mathrm{~S}$ : $22 \pm 4 \%$, and SE: $33 \pm 4 \%$ ), and the number of adult workers that were still alive at the end of the experiment had no effect on it $\left(\chi_{1,69}^{2}=2.63, P=0.105\right)$. We observed a general trend of pupae production such that $\mathrm{E}<\mathrm{S}<\mathrm{W}$; no difference was seen between diets with and without elaiosomes (W vs. WE), and only a small difference in the production of male pupae was detected between $\mathrm{S}$ versus SE diets (pair-wise comparison tests $P<0.05$ ).
The percentages of each pupa type produced were significantly different for different diets (worker; $\chi^{2} 4,69=43.42$, $P<0.001 ;$ queen; $\chi_{4,69}^{2}=13.16, \quad P=0.011$, and male; $\chi^{2} 4,69=20.76, \quad P<0.001$, Fig. 2). Pair-wise comparison tests were not significant when elaiosome-supplemented and non-supplemented diets were compared (W vs. WE and $\mathrm{S}$ vs. SE), except in the case of males (Fig. 2, $P<0.005$ ).

The dry weights of individual worker and queen pupae differed significantly among diets $\left(\mathrm{F}_{4,127}=3.52, P=0.009\right.$ and $\mathrm{F}_{4,111}=8.49, P<0.001$, respectively). Again, this was mostly as a result of the lower weight of pupae in the elaiosomeonly diet (posthoc $P<0.05$, Fig. 2). Male weight was not significantly different between diets $\left(F_{4,38}=2.62, P=0.059\right)$.

\section{Dietassimilation}

All diets were consumed but not in their totality, indicating that the amount of resources was not limiting. Moreover, only the elaiosome part of the diaspores was consumed. $\delta^{15} \mathrm{~N}$ and $\mathrm{C} / \mathrm{N}$ values differed significantly among diets $\left(\delta^{15} \mathrm{~N}\right.$ : $F_{2,12}=92.62, P<0.001$ and $\left.\mathrm{C} / \mathrm{N}, F_{2,12}=256.84, P<0.001\right)$. Posthoc Tukey's tests were significant for all combinations $(P<0.05)$, meaning that each diet was different from the others (diet $\mathrm{W}: \delta^{15} \mathrm{~N}=5.35 \pm 0.39 \%$ o, $\mathrm{C} / \mathrm{N}=4.19 \pm 0.12$; diet S: $\delta^{15} \mathrm{~N}=3.05 \pm 0.66 \%$ o, $\mathrm{C} / \mathrm{N}=14.96 \pm 0.66$, and diet $\mathrm{E}$ : $\delta^{15} \mathrm{~N}=-3.32 \pm 0.27 \%$ o, $\mathrm{C} / \mathrm{N}=28.35 \pm 1.12$, mean $\left.\pm \mathrm{SE}\right)$.

At the beginning of the experiment, the larvae had a significantly lower $\delta^{15} \mathrm{~N}$ value and a significantly higher $\mathrm{C} / \mathrm{N}$ ratio than the adult workers (Fig. $3 ; F_{1,28}=8.36, P=0.007$ and $F_{1,28}=22.06, P<0.001$, respectively). At the end of the experiment, $\delta^{15} \mathrm{~N}$ and $\mathrm{C} / \mathrm{N}$ values for larvae and workers differed significantly among diets (we added the initial values as a diet variable-larva: $\delta^{15} \mathrm{~N}: F_{5,48}=5.42, P<0.001$ and $\mathrm{C} / \mathrm{N}, \quad F_{5,48}=4.10, \quad P=0.004$, and worker: $F_{5,67}=2.62$, $P=0.032$ and $\mathrm{C} / \mathrm{N}, F_{5,67}=12.29, P<0.001$, Fig. 4). The posthoc Tukey's test showed that for both larvae and workers, $\delta^{15} \mathrm{~N}$ did not differ significantly between the beginning and 


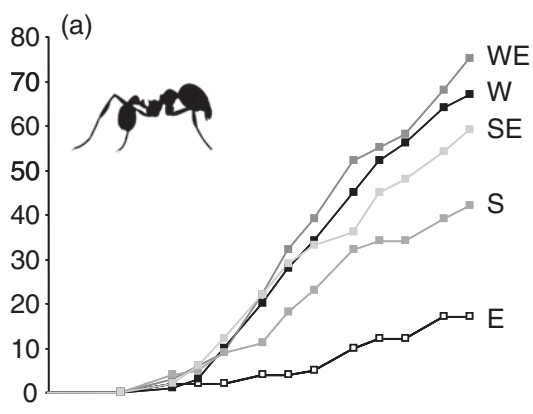

(d)

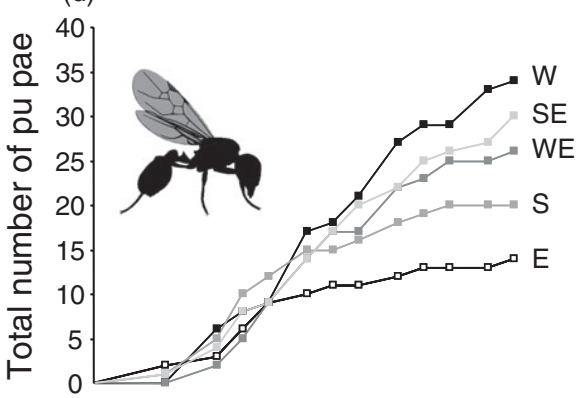

(g)

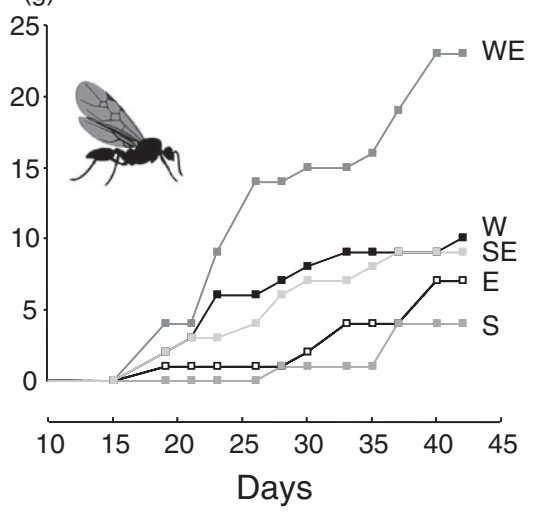

(b)
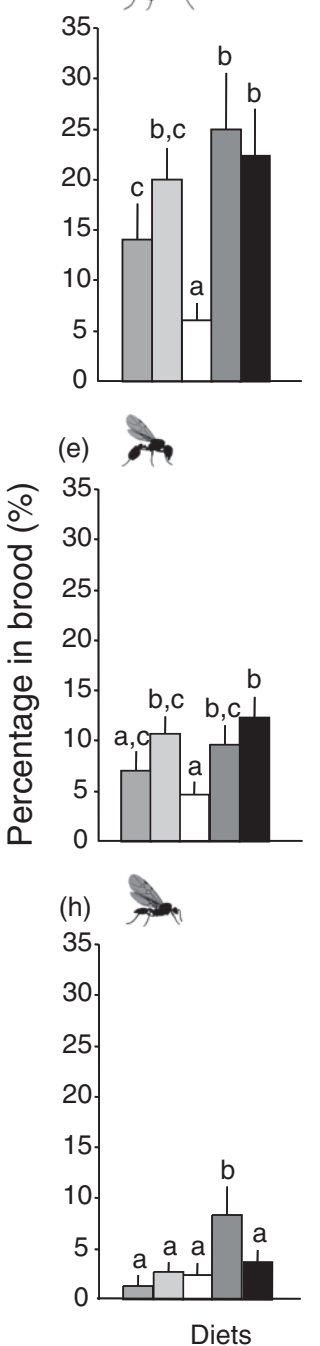

(c)
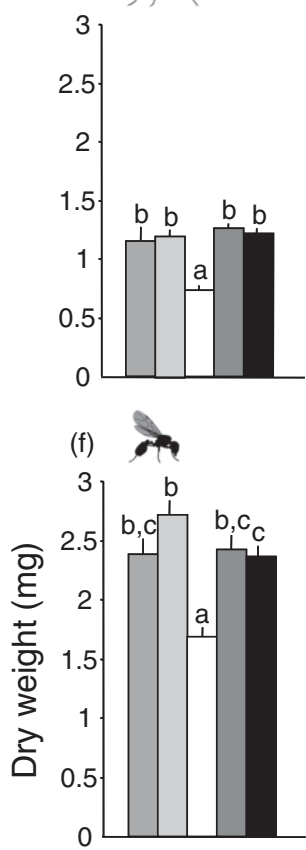

(i)

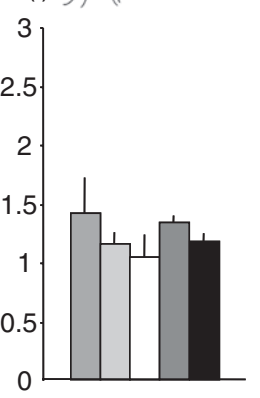

$\square S \square$ SE $\square$ E WE $\square$ W

Fig. 2. (a,d,g) Total number produced, (b,e,h) percentage of brood (mean $\pm \mathrm{SE}$ ), and (c,f,i) dry weight (mean \pm SE) of different pupa types [worker $(\mathrm{a}, \mathrm{b}, \mathrm{c})$-queen $(\mathrm{d}, \mathrm{e}, \mathrm{f})-$-male $(\mathrm{g}, \mathrm{h}, \mathrm{i})]$ for the five diets (S, ES, E, WE and W, 15 orphan groups for each diet, see details in methods section). Different letters represent the significant differences found between different diets for each pupa caste $(P<0.05)$ using a Tukey's HSD posthoc test.

the end of the experiment for the various diets, except in the case of the SE diet for larvae $(P<0.05$, Fig. 3$)$. We also observed that the $\mathrm{C} / \mathrm{N}$ ratios at the beginning and the end of the experiment were not significantly different between diets, except for $\mathrm{S}$ and $\mathrm{SE}$ workers.

The $\delta^{15} \mathrm{~N}$ and $\mathrm{C} / \mathrm{N}$ values of pupae produced during the experiment differed significantly between pupa types $\left(\delta^{15} \mathrm{~N} ; F_{2,184}=14.13, P<0.001\right.$, and $\mathrm{C} / \mathrm{N} ; F_{2,184}=32.22$, $P<0.001)$ and diets $\left(\delta^{15} \mathrm{~N} ; F_{3,184}=25.38, \mathrm{P}<0.001\right.$, and $\left.\mathrm{C} / \mathrm{N} ; F_{3,184}=12.01, P<0.001\right)$. Variations in $\delta^{15} \mathrm{~N}$ values between diets followed the same trend for the three pupa types, such that $\mathrm{S}<\mathrm{SE}<\mathrm{WE}<\mathrm{W}$, as confirmed by the nonsignificance of the diet $\times$ pupa type interaction $\left(F_{6}, 184=0.99\right.$, $P=0.069)$. The interaction was significant for the $\mathrm{C} / \mathrm{N}$ ratio
$\left(F_{6,184}=6.10, P<0.001\right.$, Fig. 4) without showing a clear pattern. Posthoc analysis of the effect of diet on $\delta^{15} \mathrm{~N}$ values showed that all diets were significantly different. As for the effect of pupa type, the mean $\delta^{15} \mathrm{~N}$ value of queens was significantly higher than that of workers or males $(P<0.05)$.

\section{Discussion}

\section{Doeselaiosomesupplementationaffectlarvaldevelopment?}

Few studies have assessed the potential positive effect of elaiosome consumption in relation to colony productivity (Table 1), and no consensus has been found in their results. 


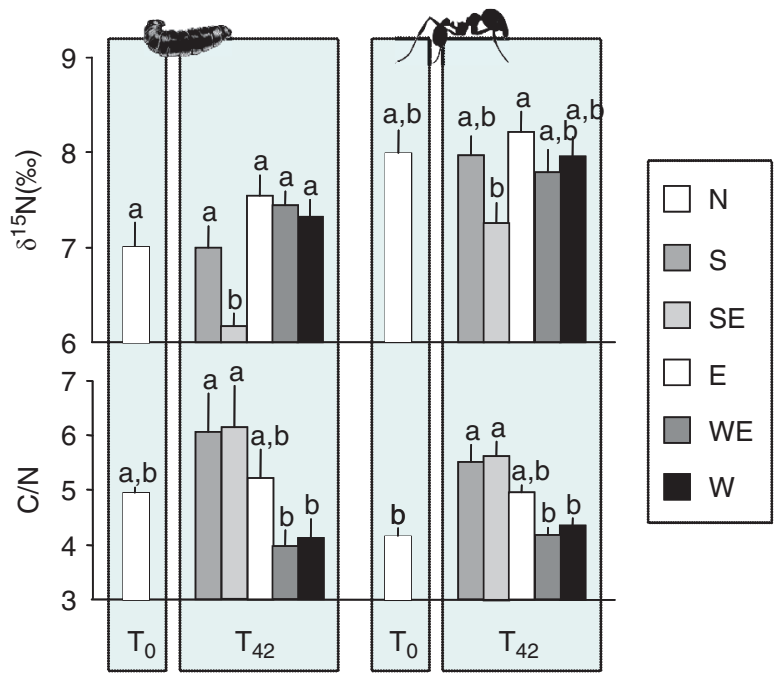

Fig. 3. Variation in $\delta^{15} \mathrm{~N}$ and $\mathrm{C} / \mathrm{N}$ ratio values (mean $\pm \mathrm{SE}$ ) of larvae and adult workers; at the beginning of the experiment (N, Natural diet, $\mathrm{T}_{0}$ ) and at the end of the experiment $\left(\mathrm{T}_{42}\right)$ for the five diets $(\mathrm{S}, \mathrm{SE}, \mathrm{E}$, WE, and W, see details in methods section). Different letters represent the significant differences between diets found for larvae and adult workers $(P<0.05)$ using a Tukey's HSD posthoc test.

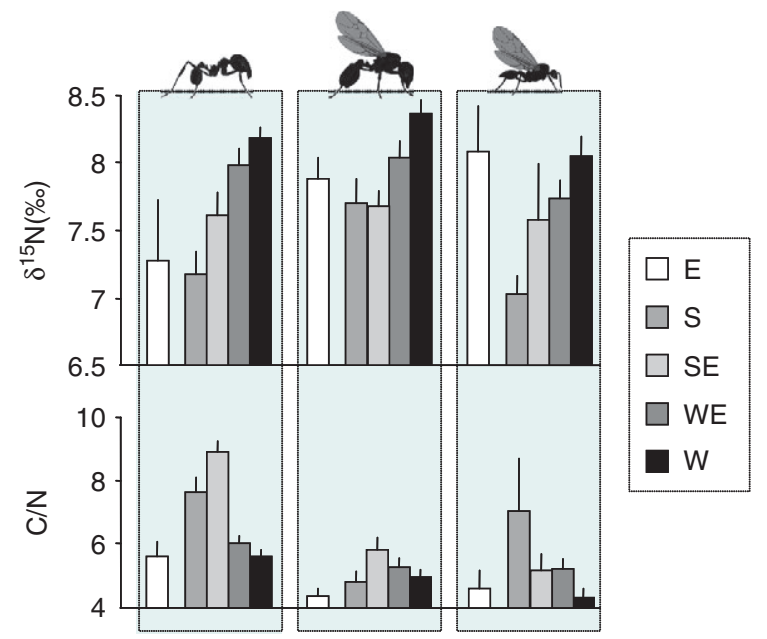

Fig. 4. Variation in $\delta^{15} \mathrm{~N}$ and $\mathrm{C} / \mathrm{N}$ ratio values (mean $\pm \mathrm{SE}$ ) among pupa types (worker-queen-male) and diets (E, S, SE, WE and E). Because the production in the diet $\mathrm{E}$ treatment was very low compared with the other four, we represented these values separately.

The general idea is that elaiosome consumption could increase the productivity of the colony and skew the sex ratio towards queens. However, it is very difficult to determine the specific role of elaiosomes in such sex ratio variation. All changes in colony production (e.g. larval production, queen production, and larval weight) could be a consequence of either (1) elaiosomes' specific nutritional contribution or (2) a nonspecific increase of food availability. Although we found that pupae production was progressively greater for certain diets $(\mathrm{E}<\mathrm{S}<\mathrm{W})$, the effect of elaiosome supplementation on pupae production and the percentage of different pupa types (for diets $\mathrm{W}$ vs. WE and $\mathrm{S}$ vs. SE) was not clear.

According to the first possibility, changes in sex allocation induced by elaiosome consumption would be as a result of the quality of their composition. In this case, elaiosome-specific nutrients might have changed the development of diploid larvae into a worker or queen. This is supported by the results of Morales and Heithaus (1998) who found a higher proportion of diploid larvae developed into queens when they were provided with elaiosomes (Table 1). In contrast, the present results do not support this hypothesis; sexual production, allocation, and weight did not differ significantly between elaiosomesupplemented and unsupplemented diets (diets W vs. WE and $\mathrm{S}$ vs. SE). If elaiosome-specific constituents play a role in caste determination such that diets containing elaiosomes favour the production of queens, it would imply that queens consume more elaiosomes than do other castes. We found no significant difference between the isotopic values of queens and workers fed elaiosome-supplemented versus unsupplemented diets. Consequently, we suggest that in this study system there is no relation between specific elaiosome consumption and caste determination.

The genetic versus environmental determination of larval caste fate has been a long debate in social insect studies. Although a few recent studies have clearly shown a genetic base for worker-queen differentiation, the environment is still considered a major cue inducing queen development (Leniaud etal ., 2012; Schwander \& Keller, 2012). Queens are generally bigger than workers and must receive a larger food intake. Recently, Smith and Suarez (2010) distinguished pupae developing into males, queens, larger workers, and smaller workers based on nitrogen isotopic values, with higher values being seen for sexuals (about 1\%o). However, this result does not show that larval caste fate is determined by food. Hence, the observed differences could be a consequence, and not a cause, of larvae developing into queens. Workers could recognise queen-developing larvae (e.g. Wheeler, 1986; Passera etal ., 1995) and feed them a different diet, which would increase size differences. In this case, a difference in diet would not determine whether a larva develops into a queen or worker.

\section{Whatistheimportanceofelaiosomeassimilation?}

In spite of direct observations of elaiosomes entering and exiting the nest, the actual fate of the diaspores in the colony remains largely unknown. Fischer et al . (2005) tested elaiosome consumption and assimilation by $M$. rubra larvae using Corydaliscava elaiosomes enriched in ${ }^{15} \mathrm{~N}$. The results showed an important enrichment of larvae receiving an elaiosome-supplemented diet. However, the artificial ${ }^{15} \mathrm{~N}$ enrichment $\left(\delta^{15} \mathrm{~N}=11737 \%\right.$ ogainst $\sim 10 \%$ in the wild $)$ may have complicated the interpretation of the results and contaminated the samples (e.g. larvae gut content or diet dust was present on the individuals). In this study, we used different dietary treatments that incorporated three resources demonstrating a natural gradient in $\delta^{15} \mathrm{~N}(\mathrm{E}<<\mathrm{S}<\mathrm{W})$ and $\mathrm{C} / \mathrm{N}(\mathrm{W}<\mathrm{S}<\mathrm{E})$. Thus, if ants consumed elaiosomes, their 
isotopic values would be much lower and their $\mathrm{C} / \mathrm{N}$ values much higher than if they had consumed the $\mathrm{W}$ and $\mathrm{S}$ diets. Adult workers did not differ isotopically between the beginning and the end of the experiment, except for some in the SE diet (Fig. 3). These small differences in isotopic values between workers could be as a result of the longer isotopic turnover time in workers' tissues or worker transfer of tissues synthesised with anterior diet, as consumption in these stock tissues. For pupae, all these tissues were synthesised during the experiment, and significant differences were found among diets that followed a general isotopic trend $(\mathrm{S}<\mathrm{SE}<\mathrm{WE}<\mathrm{W}$; we excluded the diet E, see results section, Fig. 4). The isotopic values of pupae on single component diets ( $\mathrm{S}$ and $\mathrm{W})$ were logically explained by isotopic incorporation theory. The isotopic value of pupae $=$ the isotopic value of their diet + the discrimination factor $(+3 \%$ by Feldhaar et al ., 2010). However, when we compared the isotopic values of pupae single component diets with those of their elaiosomesupplemented counterparts ( $\mathrm{S}$ vs. SE and W vs. WE), the results were more complex. Surprisingly, SE pupae were slightly more enriched in ${ }^{15} \mathrm{~N}$ than $\mathrm{S}$ pupae. This alteration could result from indirect diet transfer by differences in workers owing to SE diet (e.g. stock tissues, Caut etal ., unpubl. data). Nevertheless, it is clear that the assimilation of elaiosomes occurred, although it was low. Indeed, in the event of high elaiosome assimilation, the $\delta^{15} \mathrm{~N}$ values of pupae would tend to resemble those of elaiosomes and the discrimination factor would be more negative. We observed an increase in the $\mathrm{C} / \mathrm{N}$ ratio, confirming a modest assimilation. Inversely, $\mathrm{WE}$ pupae were less enriched in ${ }^{15} \mathrm{~N}$ and had a higher $\mathrm{C} / \mathrm{N}$ ratio than the $\mathrm{W}$ pupae. Thus, here too, an indirect consumption via worker diet transfer could complicate the interpretation of our results (e.g. trophic eggs), but, although low, elaiosome assimilation did happen. Hence, it is important to note that stable isotopes provide information on assimilated foods in addition to ingested foods, and, although the relationship between the consumption and assimilation of elaiosomes was not simple, our results confirm the direct observations of consumption.

It is very difficult to determine the importance of elaiosomes in an ant's diet in the wild. We have no information on how elaiosomes may 'compete' with the natural prey (such as insects) exploited by ants. From their laboratory study, Fischer etal . (2005) concluded that the ants preferred elaiosomes to an artificial diet. In our experiment, diet constituents were not limiting and we did not observe a preferential assimilation of elaiosomes as compared with seeds or worms. Elaiosomes are nutrient rich and contain lipids, proteins, starch, sugars, vitamins, and essential nutrients that cannot be synthesised by ants, such as linoleic acid and sterols (Gammans etal ., 2005), yet ants do not base their main diet upon them. Moreover, if ants used only these resources, worker survival and brood production would be severely reduced compared with that of ants eating a worm or seed diet. Marussich (2006) found the same trend for the survival and brood production of semi-claustral foundresses. Thus, it might be more accurate to consider the elaiosome as just an alternative resource, rather than an essential part of the ant diet, providing specific nutrients.

\section{Mutualism?}

Although elaiosomes are nutrient rich, the present results have failed to show a preference of ants for them (especially when ants are manipulated, because then it is not a real choice). Their specific constituents are also known to be inferior compared with other potential resources, such as prey (Hughes et al ., 1994). These results tend to confirm the preference for insect items over elaiosomes found in field studies (e.g. Heithaus etal ., 2005). Elaiosome consumption alone does not result in a normal level of colony production (Marussich, 2006; this study). In association with other dietary components, it neither increased total larval production nor the proportion of queens. Therefore, the qualitative hypothesis could probably be dismissed. On the other hand, elaiosomes could represent a basic dietary addition that could modify the production of the colony (the quantitative hypothesis). In this case, it is not the elaiosome constituents themselves that are important, but rather the increase in overall resource availability that they represent. Many previous studies have shown that many alterations in colony output occur subsequent to an increase in resources (e.g. Deslippe \& Savolainen, 1994, 1995; Herbers \& Banschbach, 1998; Aron et al ., 2001; Bono \& Herbers, 2003; Brown \& Keller, 2006). Moreover, in the presence of a mutualistic interaction, elaiosomes should represent a less costeffective dietary strategy. Indeed, ants transport diaspores, but only a small part is consumed, the elaiosome.

In conclusion, the mutualistic aspects of myrmechory remain unclear, especially with regards to the estimated benefits to ants. Even although it does not provide a clear advantage for both partners, myrmecochory may persist as a by-product mutualism (like the symbiosis between ants and litter trapping epiphytes, Fayle et al ., 2012). Indeed, by-product benefits are derived from self-serving behaviours (Connor, 1986): behaviours or other attributes of $A$ designed to benefit $A$ incidentally benefit $B$. The benefit to $B$ comes at no additional cost to $A$ (Connor, 1995). Thus, the production of elaiosomes by plants represents a benefit to the plants themselves and, for ants, elaiosomes represent a resource among others, without really being selected or causing specific effects. This pervasive category of cooperation encompasses an astonishing range of inter- and intra-specific phenomena in the wild (e.g. group formation and Mullerian mimicry; Connor, 1995, 2010). Thus, there is an important bias in the studies addressing mutualistic interactions, which focus more on the plant rather than the ant benefits, consequently limiting the understanding of the evolutionary mechanism. We encourage scientists studying plant-ant interactions to develop more experimental studies to address the real benefits of elaiosomes for the ant colony. In this context, we demonstrate that the use of stable isotopes represents an interesting tool, which unfortunately remains underused for these taxa.

\section{Acknowledgments}

We wish to thank J. Pearce-Duvet for improvement of the English. This work was funded by MICINN (project CONSOLIDER-MONTES CSD2008-00040), MICINN, 
FEDER (projects CGL2009-12472 to RB and CGL200909690 to XC), and the Consejo Superior de Investigaciones Cientıficas (JAE postdoctoral contract to S.C.). The authors would like thank the authorities of Doñana Natural Park for granting them permission to conduct research in the park.

\section{References}

Aranda-Rickert, A. \& Fracchia, S. (2010) Diplochory in two Jatropha (Euphorbiaceae) species of the Monte Desert of Argentina. Austral Ecology, 35, 226-235.

Aron, S., Keller, L. \& Passera, L. (2001) Role of resource availability on sex, caste and reproductive allocation ratios in the Argentine ant, Linepithemahumile . JournalofAnimalEcology , 70, 831-839.

Bono, J.M. \& Heithaus, E.R. (2002) Sex ratios and the distribution of elaiosomes in colonies of the ant, Aphaenogasterrudis . Insectes Sociaux, 49, 320-325.

Bono, J.M. \& Herbers, J.M. (2003) Proximate and ultimate control of sex ratios in Myrmicabrevispinosa colonies. Proceedingsofthe RoyalSocietyB:BiologicalSciences , 270, 811-817.

Boulay, R., Coll-Toledano, J. \& Cerda, X. (2006) Geographical variations in Helleborous foetidus elaiosome lipid composition: implications for dispersal by ants. Chemoecology, 16, 1-7.

Boulay, R.F., Carro, F., Soriguer, R.C. \& Cerda, X. (2007a) Synchrony between fruit maturation and effective dispersers' foraging activity increases seed protection against seed predators. Proceedingsofthe RoyalSocietyB:BiologicalSciences , 274, 2515-2522.

Boulay, R., Hefetz, A., Cerda, X., Devers, S., Francke, W., Twele, R., etal . (2007b) Production of sexuals in a fission-performing ant: dual effects of queen pheromones and colony size. BehavioralEcology andSociobiology, 61, 1531-1541.

Boulay, R., Cerda, X., Fertin, A., Ichinose, K. \& Lenoir, A. (2009) Brood development into sexual queens depends on the presence of a queen but not on temperature in an ant dispersing by colony fission, Aphaenogastersenilis . EcologicalEntomology , 34, 595-602.

Bronstein, J.L. (1994) Our current understanding of mutualism. The QuarterlyReview ofBiology , 69, 31-51.

Brown, W.D. \& Keller, L. (2006) Resource supplements cause a change in colony sex-ratio specialization in the mound-building ant. BehavioralEcologyandSociobiology , 60, 612-618.

Carroll, C.R. \& Janzen, D.H. (1973) The ecology of foraging by ants. AnnualReviewofEcology,Evolution, andSystematics ， 4, 231-258.

Caut, S., Angulo, E. \& Courchamp, F. (2009) Variation in discrimination factors $(\triangle 15 \mathrm{~N}$ and $\triangle 13 \mathrm{C})$ : the effect of diet isotopic values and applications for diet reconstruction. JournalofAppliedEcology , 46, 443-453.

Connor, R.C. (1986) Pseudoreciprocity: investing in mutualism. AnimalBehaviour, 34, 1562-1566.

Connor, R.C. (1995) The benefits of mutualism: a conceptual framework. BiologicalReviews , 7, 427-457.

Connor, R.C. (2010) Cooperation beyond the dyad: on simple models and a complex society. Proceedings of the Royal Society B: BiologicalSciences, 365, 2687-2697.

Deslippe, R.J. \& Savolainen, R. (1994) Role of food supply structuring a population of Formica ants. Journal of Animal Ecology , 63, 756-764.

Deslippe, R.J. \& Savolainen, R. (1995) Sex investment in a social insect: the proximate role of food. Ecology, 76, 375-382.

Fayle, T.M., Edwards, D.P., Turner, E.C., Dumbrell, A.J., Eggleton, P. \& Foster, W.A. (2012) Public goods, public services and by-product mutualism in an ant-fern symbiosis. Oikos, 121, 1279-1286.

Feldhaar, H., Gebauer, G. \& Blüthgen, N. (2010) Stable isotopes: past and future in exposing secrets of ant nutrition (Hymenoptera: Formicidae). MyrmecologicalNews, 13, 3-13.
Fischer, R.C., Ölzant, S.M., Wanek, W. \& Mayer, V. (2005) The fate of Corydalis cava elaiosomes within an ant colony of Myrmica rubra: elaiosomes are preferentially fed to larvae. InsectesSociaux, 52, 55-62.

Fischer, R., Richter, A., Hadacek, F. \& Mayer, V. (2008) Chemical differences between seeds and elaiosomes indicate an adaptation to nutritional needs of ants. Oecologia, 155, 539-547.

Fokuhl, G., Heinze, J. \& Poschlod, P. (2007) Colony growth in Myrmica rubra with supplementation of myrmecochorous seeds. EcologicalResearch, 22, 845-847.

Fokuhl, G., Heinze, J. \& Poschlod, P. (2011) Myrmecochory by small ants-Beneficial effects through elaiosome nutrition and seed dispersal. ActaOecologica, 38, 71-76.

Gammans, N., Bullock, J.M. \& Schçnrogge, K. (2005) Ant benefits in a seed dispersal mutualism. Oecologia, 146, 43-49.

Gammans, N., Bullock, J.M., Gibbons, H. \& Schönrogge, K. (2006) Reaction of mutualistic and granivorous ants to Ulex elaiosome chemicals. JournalofChemicalEcology , 32, 1935-1947.

Giladi, I. (2006) Choosing benefits or partners: a review of the evidence for the evolution of myrmecochory. Oikos, 112, 481-492.

Gomez, C., Espadaler, X. \& Bas, J.M. (2005) Ant behaviour and seed morphology: a missing link of myrmecochory. Oecologia, 146, 244-246.

Heithaus, E.R., Heithaus, P.A. \& Liu, S.Y. (2005) Satiation in collection of myrmecochorous diaspores by colonies of Aphaenogaster rudis (Formicidae: Myrmicinae) in Central Ohio, USA. Journalof InsectBehavior, 18, 827-846.

Herbers, J.M. \& Banschbach, V.S. (1998) Food supply and reproductive allocation in forest ants: repeated experiments give different results. Oikos, 83, 145-151.

Herrera, C.M. (2005) Seed dispersal by vertebrates. Plant-Animal Interactions:AnEvolutionaryApproach (ed. by C. M. Herrera and O. Pellmyr), pp. 185-208. Blackwell Science, Oxford, U.K.

Hölldobler, B. \& Wilson, E.O. (1990) TheAnts . Harvard University Press, Cambridge, Massachusetts.

Hughes, L., Westoby, M. \& Jurado, E. (1994) Convergence of elaiosomes and insect prey: evidence from ant foraging behaviour and fatty acid composition. FunctionalEcology, 8, 358-365.

Lengyel, S., Gove, A.D., Latimer, A.M., Majer, J.D. \& Dunn, R.R. (2010) Convergent evolution of seed dispersal by ants, and phylogeny and biogeography in flowering plants: a global survey. PerspectivesinPlantEcology , 12, 43-55.

Leniaud, L., Darras, H., Boulay, R. \& Aron, S. (2012) Social hybridogeneis in the clonal ant Cataglyphis hispanica. Current Biology, 22, 1188-1193.

MacRaild, L.M., Radford, J.Q. \& Bennett, A.F. (2010) Non-linear effects of landscape properties on mistletoe parasitism in fragmented agricultural landscapes. LandscapeEcology , 25, 395-406.

Manzaneda, A.J., Rey, P.R. \& Boulay, R.R. (2007) Geographic and temporal variation in the ant-seed dispersal assemblage of the perennial herb Helleborusfoetidus L. (Ranunculaceae). Biological JournaloftheLinneanSociety , 92, 135-150.

Marussich, W.A. (2006) Testing myrmecochory from the ants perspective: the effects of Datura wrightii and D. discolor on queen survival and brood production in Pogonomyrmexcalifornicus . Insectes Sociaux, 53, 403-411.

Morales, M.A. \& Heithaus, E.R. (1998) Food from seed-dispersal mutualism shifts sex ratios in colonies of the ant Aphaenogaster rudis. Ecology, 79, 734-739.

Ness, J.H., Morin, F. \& Giladi, I. (2009) Uncommon specialization in a mutualism between a temperate herbaceous plant guild and an ant: are Aphaenogaster ants keystone mutualists? Oikos, 118, 1793-1804. 
Passera, L., Aron, S. \& Bach, D. (1995) Elimination of sexual brood in the Argentine and Linepithemahumile: queen effect and brood recognition. EntomologiaExperimentalisetApplicata , 75, 203-212.

Pfeiffer, M., Huttenlocher, H. \& Ayasse, M. (2010) Myrmecochorous plants use chemical mimicry to cheat seed-dispersing ants. FunctionalEcology , 24, 545-555.

Pizo, M.A. \& Oliveira, P.S. (2001) Size and lipid content of nonmyrmecochorous diaspores: effects on the interaction with litter foraging ants in the Atlantic rain forest of Brazil. PlantEcology, 157, 37-52.

Schwander, T. \& Keller, L. (2012) Evolution: sociality as a driver of unorthodox reproduction. CurrentBiology, 22, R525-R527.

Servigne, P. \& Detrain, C. (2010) Opening myrmecochory's black box: what happens inside the ant nest. Ecological Research, 25, 663-672.

Smith, C.R. \& Suarez, A.V. (2010) The trophic ecology of castes in harvester ant colonies. FunctionalEcology , 24, 122-130.
Van Ommeren, R.J. \& Whitham, T.G. (2002) Changes in interactions between juniper and mistletoe mediated by shared avian frugivores: parasitism to potential mutualism. Oecologia, 130, 281-288.

Vereecken, N.J. \& McNeil, J.N. (2010) Cheaters and liars: chemical mimicry at its finest. CanadianJournalofZoology , 88, 725-752.

Wheeler, D.E. (1986) Developmental and physiological determinants of caste in social Hymenoptera: evolutionary implications. American Naturalist, 128, 13-34.

Willson, M.F. \& Traveset, A. (2000) The ecology of seed dispersal. Seeds:TheEcologyofRegenerationinPlantCommunities , 2nd edn (ed. by M. Fenner), p. 85. CAB International, Wallingford, U.K.

Zelikova, T.J., Dunn, R.R. \& Sanders, N.J. (2008) Variation in seed dispersal along an elevational gradient in Great Smoky Mountains National Park. ActaOecologica, 34, 155-162. 